\title{
Teaching to the Test: Approaches to Teaching in Senior Secondary Schools in the Context of Curricullum Reform in China
}

\author{
Mingren Zhao ${ }^{1 *}$, Baolong $\mathrm{Mu}^{1}$, Chunping $\mathrm{Lu}^{2}$ \\ ${ }^{1}$ School of Education, Northwest Normal University, Lanzhou, China \\ ${ }^{2}$ Department of Sociology, Northwest Normal University, Lanzhou, China \\ Email: "zhaomingren@hotmail.com
}

Received 22 November 2015; accepted 19 January 2016; published 22 January 2016

Copyright (C) 2016 by authors and Scientific Research Publishing Inc.

This work is licensed under the Creative Commons Attribution International License (CC BY). http://creativecommons.org/licenses/by/4.0/

CC) (i) Open Access

\begin{abstract}
It has been proved in the past half century that high-stakes tests hinder more than promote instruction. The College Entrance Examination (CEE) in China has thus been in widely questioned. When it comes to curriculum reform this century, the question becomes how has curriculum reform been implemented in the classroom? What role does the CEE play in it? A qualitative study of three high schools of different levels in a city of central China shows that transmission classes emphasizing teachers' cramming and students' passive memorizing are predominant in classrooms, with about one-third of comprehensive classes based on constructivism. Transformative classes calling for students' positive inquisition and comprehensive development are still highly unusual. The CEE is a "ferocious" controller of teaching and learning. Though instruction is, in some way, promoted by CEE reform, it still has a long way to go to break itself out from a test-oriented predicament. It is, then, necessary to launch a structural reform of the CEE, change the teachers' beliefs and develop their competence in curriculum implementation.
\end{abstract}

\section{Keywords}

Approaches to Teaching, High-Stakes Teaching, Senior Secondary School, China

\section{Introduction}

Curriculum reforms in the world feature for their mutual learning and increasing common elements in this era of

\footnotetext{
"Corresponding author.
}

How to cite this paper: Zhao, M. R., Mu, B. L., \& Lu, C. P. (2016). Teaching to the Test: Approaches to Teaching in Senior Secondary Schools in the Context of Curriculum Reform in China. Creative Education, 7, 32-43. 
economical and cultural globalization (Anderson-Levitt, 2008). As an important part of its integration into this progress, China's education has seen in recent years a great influence from Western educational philosophies. In addition to the growing demand for creative participants in its economic development and worship of constructivism and humanism in the field of education, a massive, complicated curriculum reform in basic education was carried out in mainland China, appealing for the exploration of creativeness and practical ability of students (Huang, 2004).

Educational change is technically simple and socially complex; implementation consists of the process of putting into practice an idea, program, or set of activities and structures new to the people attempting or expected to change (Fullan, 2001). What about the classroom implementation of this curriculum reform launched by the Chinese central government? What are the approaches to teaching? How is it influenced by the CEE since the latter plays a big part in the distribution of educational resources and social classification in China? What is the mechanism generating this special influence? Answers to the above questions are surely helpful to our better understanding of the relationship between high-stakes tests and curriculum and instruction, as well as the environment for curriculum implementation.

\section{Theoretical Background: Approaches to Teaching and High-Stakes Tests}

\subsection{Approaches to Teaching}

Instruction is a dynamic and complex activity that is rooted in personal meaning and in dialogue about what schools should do (Miller \& Seller, 1985). What can students actually get from instruction? How is instruction carried out? How do teachers function in it? In what ways do students learn knowledge? These questions are closely related to teachers' and students' personal belief structure about the purposes and methodologies of education. We refer to these basic beliefs and practice about what schools should do and how students learn as approaches to teaching (Miller \& Seller, 1985).

According to different roles teachers play in instruction, Fenstermacher \& Soltis (2009) divided teaching into an executive approach, a facilitator approach and a liberationist approach. Another perspective for us to understand the orientation of instruction is its process. It is from this standpoint that Miller \& Seller (1985) divided the orientation of curriculum and instruction into transmission, transaction and transformation, each of which means a different view of the nature of instruction. These two differentiations are largely identical. Based on their considerations and my understanding of curriculum, I prefer a four-type division: transmission approach, understanding approach, inquiry approach and transformation approach.

\subsubsection{Transmission Approach}

The purpose of the transmission approach is to transmit facts, skills and values to students based on behavior psychology, emphasizing the acquisition of subject knowledge through memorizing and dull exercises. Teaching looks like a standardized assembly line. Teachers have absolute authority, and the teaching process is exactly prepared. Teacher initiation — student answer - teacher evaluation is the normal model (Cazden, 2001), teachers control all teaching activities, students are very passive. This kind of instruction is, according to the existentialist educational philosopher Jaspers (1983), scholastic education.

Just transmit knowledge, the teacher just follows scripts creativelessly, whereas the scripts are unchanged systems. Authoritative writers and books are worshiped and the teacher is a replaceable agent of no importance. The content of instruction is unchangeably modeled... people include their minds into a conceptual system in which they can live and exterminate their own individuality.

Both teachers and students are subordinate to books in this scholastic instruction. Since knowledge in students' mind is messy and not systematic, they cannot understand, master or apply it flexibly and productively but just put it to memory.

\subsubsection{Understanding Approach}

We define "understanding" as the capacity to use current knowledge, concepts, and skills to illuminate new problems or unanticipated issues. We believe that teaching for understanding aims for "uncoverage" rather than for "coverage", and the greatest enemy of understanding is coverage (Gardner \& Boix-Mansilla, 1994). Understanding needs students' greater ability to generate qualitative representations of problems and, in particular, re- 
presentations that require familiarity with concepts, principles, and relationships that are not explicit in surface descriptions of the problems.

The students thus need a dialogue with the course for an understanding of the essence of facts, concepts, models, theories, the relationship between them and that between new and mastered knowledge, then they are able to knit messy knowledge into a whole system (Nickerson, 1985). Learning is not discovering more, but interpreting through a different scheme or structure (Brooks \& Brooks, 1993). Understanding can satisfy deeply learning needs, can facilitate learning, can also make someone want to learn more; understanding is the capacity to respond flexibly in different situations.

\subsubsection{Inquiry Approach}

The most important objective of learning is knowledge structure in both transmission and understanding approaches. But when it comes to the inquiry approach, it becomes the cultivation of students' interest, competence, determination to learn and their understanding, method and values of multi-perspective inquiry. Learners are usually confronted with anxieties, funny things or problems in their lives and study. When they decide to face them frankly, they start their reflective thinking.

This approach of learning incarnates a fundamental spirit of scientific research aims for problem solution and knowledge production, there's no fixed instruction mode and both teachers and students can think freely and realize their poor understanding of truth through endless questioning. The teacher inspires and reinforces students' responsibility for learning. The learners experience not only a development of knowledge and ability, but also a sense of internal satisfaction and self-efficacy, which works as the internal motivation for continuing inquiry learning.

\subsubsection{Transformative Approach}

The transformative approach holds a belief of humanism and social reconstruction. On the one hand, it believes that humans are naturally good and the aim of instruction is the all-round development and individual liberation of students. Learning is not an external controlling power but a mental liberation; the objective of education lies in helping students in their constant self-realization. On the other hand, it believes that education is the fundamental method for social change (Dewey, 1966), and to educate sympathetic, righteous and active citizens is to form a main force in the development of a fairer society. Learning through transformative instruction means bringing changes in people by looking at things in different ways. Palmer (2007) once gave a vivid description of different classes:

If we regard truth as something handed down from authorities on high, the classroom will look like a dictatorship. If we regard truth as a fiction determined by personal whim, the classroom will look like anarchy.

If we regard truth as emerging from a complex process on mutual inquiry, the classroom will look like a resourceful and interdependent community.

Transformative instruction is an open, pluralistic community in which students are active, enterprising, and have a clear consciousness of individuality.

\subsection{The Relationship between High-Stakes Tests and Approaches to Teaching}

A test is high-stakes when its results are used to make important decisions that affect students, teachers, administrators, schools, and districts (Madaus, 1988a). The effect of testing on teaching and learning is called "washback". Washback, at a macro level, refers to the extent to which a test influences within the society, ranging from government policymaking, school administration, publishing, and general opportunities, to parents' expectations of their children. At a micro level, washback refers to the extent to which a test influences within the classroom, mainly in the change or innovation of curricula and teachers' methodologies and the influence of students' learning (Chapman \& Snyder, 2000). Claims are made for both negative and positive washback (Alderson \& Wall, 1993).

Using the method of qualitative metasynthesis, Au (2007) analyzes 49 qualitative studies to interrogate how high-stakes testing affects curricula. The findings of the study suggest that the nature of high-stakes-test-induced curricular control is highly dependent on the structure of the tests themselves. The positive washback lies in face that tests have symbolic power in the minds of policymakers and the general public. The numerical scores from 
high-stakes tests have an objective, scientific, almost magical persuasiveness about them that the general public and policymakers are quick to accept. Test results become a synecdoche for standards. Test results can have in creating an image of progress or reform (Madaus, 1988a).

Properly conceived and implemented measurement-driven instruction can constitute a potent force for educational improvement, and can improve student performance on high-stakes tests follows (Popham, 1987). When it comes to instruction, through tests teaching materials can be quickly modified and teachers' classroom attitudes and behaviors can be changed. An investigation carried out in six provinces of a four-year high school English curriculum reform in mainland China shows that there exists marked positive washback: for example, teaching materials have been expanded to include a greater use of imported and self-compiled materials; there have also been changes in what makes up the lessons ( $\mathrm{Li}, 1990)$.

The negative washback, however, constitutes a larger part. Examinations have seen a quick development and sharp changes since the 1960s and have profoundly influenced the content and methods of instruction. What is assessed becomes what is valued, which becomes what is taught. Teachers' classroom practices are increasingly standardized by high-stakes testing and a scripted curriculum. Public school teachers in the US are teaching under what might be considered the "New Taylorism", where their labour is controlled vis-à-vis high-stakes testing and pre-packaged, corporate curricula aimed specifically at teaching to the tests (Au, 2011). High-stakes testing is fast usurping the role of the curriculum as the mechanism for defining what schooling is about, determining what is taught, how it is taught, what is learnt, and how it is learnt (Luo, 2012).

Tests can become the ferocious masters of the educational process, not the compliant servants they should be. The primary effect of high-stakes testing is that curricular content is narrowed to tested subjects, subject area knowledge is fragmented into test-related pieces, and teachers increase the use of teacher-centered pedagogies (Au, 2007). High-stakes testing constrains the creativity and spontaneity of teachers and students, and finally demeans teachers' professional judgment; what matters more is that there is a consequent change in teachers' beliefs (Chapman \& Snyder, 2000).

China is the hometown of examinations. The Imperial Examination [Keju], implemented since the Sui Dynasty, had been working as the main way to select imperial officers and for common people to make a better living and get social and political status for about 1300 years. The function of examinations' social stratification and their consequently formed complex social values are everlasting. High school and college entrance exam results play an important role in determining transitions to secondary and tertiary education, and in determining the type of education received (Hannum, An, \& Cherng, 2011), and then determining the future career and social status of students. Out of its powerful guidance, the CEE in China controls not just high school education but the whole basic education system. Education is, then, a measurement-centered systematic project. High marks are consequently a strong, endless thirst for Chinese people, not because their educative implication or values to kids' growth, but because of the profits of social mobility and the honor it brings about. The invaluable experience of education makes way for high marks.

\section{Methods}

\subsection{Participants and Design}

Existing scales are employed to investigate teachers' approaches to the curriculum and teaching (Cheung \& Wong, 2002; Patrick, 1978). These kinds of scales mainly reveal teachers' expectations of curriculum approaches. We prefer to find out what is happening in the classroom, as we know that there is a big difference between the ideal curriculum and the operational curriculum.

Through qualitative study, we can investigate the operational curriculum by participative observation and in-depth interview and then make a systematic analysis of key elements affecting the curriculum implementation. This qualitative study explored three high schools (high schools A, B and C) in a city of China; the economical and social development of the province this city is located in is at a mediocre level and new curriculum reform has been carried out for three years. We finished our investigation in two weeks.

The city has a middle-class social and economic development and education is valued there. The three schools selected are respectively recognized as province key high school (high school A), province model high school (high school B) and common rural high school (high school C). Great disparity exists in students' enrollment requirements, teachers' competence levels, administration, policy and financial support. Key province high school enjoys priority in teacher recruitment and student enrollment. Students with marks not much higher than 
the provincial high school enrollment line only go to common rural schools. Whenever a teacher in a common high school grows to some extent excellent, he is usually scooped away by those officially recognized better schools.

Observation is carried out randomly upon a school's official recommendation and teachers' voluntary agreement in grade 10 and grade 11 students. None the 27 classes observed in the three schools (see Table 1) were specially prepared for our investigation. Deep semi-structured interviews with 27 teachers immediately follow the observation.

Taking their observed classes into consideration, we interviewed 27 teachers according to a previously prepared outline, which was based on our original plan and pre-investigation, and continuously followed up during the interview. The contents of the interview included the teacher's experience, understanding and reflection on the design of the curriculum, teaching methods, assessment and the relationship between teaching and the CEE. Then two or three students and one or two of their parents were selected for our semi-structured interview, based on the students' different achievements. The interviews with both the teachers and students were face-to-face, but the former lasted for 50 - 70 minutes and the latter for about 30 minutes. These interviews were between the investigators and their objects, with no third parties present. Surveys of some parents were made on the phone because they live far from the schools. All the interviews and observations were audiotaped and transcribed upon agreement.

\subsection{Data Analysis}

All transcripts of interviews and observations have been analyzed under the support by NIVIVO 9 software. Data analysis was divided into two parts. Classroom observation data is analyzed in the first part, interview data with teachers, students and parents is analyzed in the second part in combination with the analysis of classroom observation.

Data analysis processed in a recursive, iterative manner as two researchers moved between the data and the theoretical framework described above. In the first apart, we analyzed each classroom observation from the following five aspects according to our understanding of approaches to teaching formed in the literature review: learning outcomes, learning methods, knowledge organization, classroom control and students' participation. Analysis-based description of the characteristics of each class is used to judge its practical approaches to teaching. This is done in an open way, not trying to define it into any one of the four orientations mentioned in the literature review. In other words, a new orientation may be judged out if the class features, in fact, are markedly different from these four types mentioned above.

In the second part, we start interview analysis by word-by-word dissecting and open recoding, this involved searching for words, phases, and ideas that appeared and reappeared in the data. The codes developed were mainly folk categories that reflected the indigenous concepts used by participants (e.g., "main points of exam," "write down," "follow me" "efficiency"). There are sixty codes extracted in total. For example, one student said:

Our teacher usual says that you just memorize this, what really matter is that you can write it down on your exam papers. Accumulation makes comprehension, and you will truly understand this someday (SI-A-10Politics).

We extracted the "memorize" as the code to represent the meaning of this paragraph. Followed by categorization, conceptualization and axis classification of these "codes" into themes, which may be multilevel. Through

Table 1. Information of sampling schools.

\begin{tabular}{cccc}
\hline High school & School A & School B & School C \\
\hline Bureau of education recognition & Province key high school & Province model high school & Common rural high school \\
Population of students & 5300 & 6700 & 530 \\
Population of teachers & 500 & 9 & 9 \\
Lessons observed & 10 & 24 & 8 \\
Teachers & 10 & 18 & 26 \\
\hline
\end{tabular}


interviews, let us have a further understanding of the nature and characteristics of approaches of teaching, and found the deep relationship between teaching and examination from the view of students, teachers, parents and schools.

Data analysis and recoding are finished in the same way by two different researchers. Cohen's Kappa co-efficient analysis appears to show a good internal consistency between each "code", "theme" and "localized concept”.

\subsection{Ethics Statement}

The study was approved by the Institutional Review Board of the School of Education at Northwest Normal University. All participants gave written consent prior to investigation.

\section{Results}

\subsection{Transmission-Dominant Landscape of Instruction}

Data analysis shows that 16 out of these 27 lessons take a transmission approach, nine others an understanding approach, one an inquiry approach and the remaining one a transformation approach (see Table 2). Although changes in textbooks have promoted, to some extent, the change in teachers' beliefs and teaching styles, instruction is still, in the era of new curriculum reform, dominated by a transmission approach. Real reform is implemented limitedly in the classroom and both inquiry and transformation approaches are hard to apply. The following part will describe and analyze the nature of these orientations from the aspects of learning outcomes, learning methods, knowledge organization, classroom control and students’ participation.

\subsection{Transmission Approach: Cram in}

Twelve of the 16 classes took a transmission approach in which the teacher read according to scripts, and left their students to listen and write them down. The outcome of this approach is that students recite and memorize subject knowledge and some even deal with procedures and results of experiments in this way. Reciting plays a big part in liberal arts classes, where the teacher and his students share the same expectation of memorizing these knowledge points and solution procedures to disciplinary problems. The first step of a typical class is generally to check whether students have recited what they have "learnt" in the previous class. The check act as further consolidation for them; the last minutes are left for the students to recite, as described by one student interviewed:

Our teacher usual says that you just memorize this, what really matter is that you can write it down on your exam papers. Accumulation makes comprehension, and you will truly understand this someday (SI-A10-Politics) ${ }^{1}$.

Table 2. Statistics of approaches to teaching.

\begin{tabular}{ccc}
\hline & Teaching approach & Number \\
\hline \multirow{2}{*}{ Transmission approach } & Typically transmission & 12 \\
& Mainly transmission, slightly comprehension & 4 \\
Subtotal & Typically comprehension & 16 \\
Comprehension approach & Mainly comprehension, slightly transmission & 7 \\
& Mainly comprehension, slightly transformation & 1 \\
& Subtotal & 1 \\
& Inquiry approach & 9 \\
& Transformation approach & 1 \\
\hline
\end{tabular}

${ }^{1}$ In data source SI-A-10-Politics, "SI” stands for student interview, “TI” for teacher interview, “A” for high school A, “10” for the student’s grade, "Politics" for the curriculum. 
His teacher's words are proof of what the students told us:

When I think it's ok for activities, I'll let them do that. But after that, what I should (planned to) emphasize or confirm, I still have to cram (into them) (TI-A-10-Mathematics).

Sometimes teachers do let students discuss something, but in the students' view, the discussion is arranged for better memorization. "Write down", "memorize clearly" and "recite" are teachers' typical classroom directions. The method of instruction is usually lecturing and that of learning is typically listening, doing exercises, answering according to what the textbook says and reciting. The teacher enjoys absolute authority through textbooks, controlling the flow and speed of instruction. Students in such closed classes are left in a passive and subordinate position.

You must stay close to what is contained in the textbook, that is you can only answer based on the textbook. If you stray away from this the teacher will ask you to sit down and say that we can talk about this after class (SI-A-11-Chinese Language).

In typical transmission instructions featuring a learning style of listening and memorizing like this, students just gulp without a slight chewing. As a tradition followed by many other high schools, all three years' curricula are finished in two years to save enough time for review in grade 12.

I think that students' learning tasks are very heavy. Unless teachers give students some time during class they have no time to digest the content because they must deal with homework from nine subjects... Good students may be able to find some time to understand things on their own but most of the students can only spend their time trying to complete the assigned homework (TI-A-10-English).

Most teachers agree that instructions in grades 10 and 11 are hurry curriculum-finishings; students suffer from exhausting keep-up work. Many students cannot truly understand what they were taught in the two years' hurried curriculum and reviews in grade 12 are like new curricula they never touched. In short, textbook or subject knowledge has the absolute authority in transmission teaching. Students and teachers are both passive objects in the process. In the transmission approach, teaching becomes stimulus and response rather than a process rich in interaction and reflection. So the knowledge which students learnt is shallow, fragmented and formalist, and students are unable to apply knowledge flexibly. Failure to comprehend thoroughly keeps students from disciplinary structure construction or obtaining meaning through integration of newly learnt knowledge into the structure.

The other four classes are mainly under the transmission approach but slightly the understanding approach. What differs from those typical transmission approach ones is that a minor part of the instruction is arranged for students to understand what they were taught even though most of the class keeps to the tradition of teacher cramming and students listening. Teachers occasionally help students to appreciate and understand curriculum contents in two classes, with most effort spent on meaningless sending and receiving.

\subsection{Understanding Approach: Standardized Understanding}

There are two aspects to understanding. First, teachers can lead students to connect subject knowledge with students' daily experiences and previously acquired knowledge, generating the motivation and basis for learning new knowledge in the process of interpreting and reinterpreting experiences. Second, teachers can help students understand by explaining subject knowledge systematically. The two aspects of understanding found in this study fit with constructivism. In this process, students are active, there is a lot of interaction between teachers and students. Learning methods include listening with active cognitive engagement, discussion, sharing, and answering questions. Students experience a meaningful learning process.

Although students have time to understand the content knowledge, they are active, but do not take the initiative themselves. The space for understanding is very limited, textbooks and teachers are still the unsurpassed authority, and teachers control the scope and lines of students' thinking.

Through a relevant metaphor, appropriate guidance, a timely inspiration, it is possible to stimulate students' thinking. The result of this stimulation is to get the student to follow my line of thinking all along (TIA-10-Chinese Language).

I do speak a lot and students act less in class. They do not need to respond or act, they just need to follow me 


\section{(TI-B-11-Mathematics).}

Transmission instruction values highly the outcome useful for exams but not the learning process, while the comprehension approach emphasizes both the instructive outcome and the learning process. Yet this process is at the outcome's service. This kind of comprehension is dependent, prescribed, and its result points at standard answers on exam papers. Students' minds are regulated and of course not pluralistic here. As one teacher commented:

Students would learn lots of meaningful things in Chinese language classes if there was no college entrance examination. But in the face of the exam, students' understandings of the text are so similar, so their scores are almost the same (TI-A-11-Chinese language).

Teachers and students are, in this prescribed understanding teaching, shackled dancers. They are meaningful duplicators, they are mentally bound. Like pilgrims, students are striving for enrichment and vivification, by meaningful interpretation, of the journey to their clear, firm targets. As for the teachers, they try, to a greater degree, to figure out more attractive methods and skills to boost students' interest and self-consciousness. There is a slight change in students' target for exam achievement and plan for knowledge acquisition. This is, in essence, a spirit of perseverance in the transmission approach. Learning has no emancipatory implication. Both transmission and understanding approach control teachers' and students' minds and inhibit their inclination to negate, criticize or transcend. In Marcuse's (1964) view, there emerges a pattern of one-dimensional thought and behavior in which ideas, aspirations, and objectives that, by their content, transcend the established universe of discourse and action are either repelled or reduced to terms of this universe (Marcuse, 1964). They are redefined by the rationality of the given system and of its quantitative extension.

\subsection{Inquiry and Transformation Approaches: Freeman}

Compared with the transmission and understanding approaches, the inquiry approach values open multiple opinions. The result of learning is not merely knowledge, skills, attitudes and methods. Communication, cooperation and application are also important goals. In the transformation approach, learning outcomes focus on deepening discussion, introspection and changing students' values and social concerns. Learning methods include application, debate, expression, textbook drama, etc. Teachers and students have equal opportunity to think and express themselves freely. Words from a student:

I love singing, we learnt an article named The Dancer from Yidou, I was so moved that I sang A Thousand Miles Apart (one of Zhou Jielun's best songs) for the class. This type of class is wonderful, we love it, some comments are gorgeous. Much more efficient than direct cramming (SI-A-11-Chinese Language).

In the inquiry and transformation approaches, knowledge is integrated, disciplinary knowledge interrelates and interacts with one's experience, so does acquired knowledge with that newly learnt. Teachers change from authoritative knowledge providers and evaluators to organizers, supporters and challengers. Students can be internally satisfied, liberated and empowered in their active inquiry and reflection.

\subsection{The CEE is the Controller of Teaching and Learning}

The CEE is a double-edged sword, a promotion and at the same time the biggest obstacle to curriculum reform. The promotion of the CEE changing with curriculum reform progress lies in the fact that CEE questions become increasingly open and flexible, assessing more of students' competence of reflection and knowledge application and less rudimentary fact checking. This guides teachers to teach methods of solving problems, to broaden their horizons and help them develop consciousness and competence in flexible knowledge application. The CEE's negative effect on the curriculum is, however, even stronger. Teaching and learning, expectation from school leaders and parents all point at it and finally turn it into the dominating power of a high school. Analyses will be made from the perspectives of school administration and teachers.

\subsubsection{To Teachers: Teaching Is Directly Tied to the CEE}

A large amount of repetitive exercises is a key way to prepare for the CEE. There is a mock examination given to grade 12 students every week, which means that they practice the same type of questions and their respective solutions about 50 times (Zhou, 2008). It is suggested in The Outline of National High School Curriculum (Trial 
version) (2003) that the second term of grade 12 can be arranged for overall review. A widespread pattern in high schools is to finish all curricula in grade 11 and grade 12 to save enough review time. This structural adjustment, "the great strategy" (TI-A-11-H) to teachers, adapts instruction to a preparation for the CEE. This does, as has been stated above, great harm to students' comprehension of knowledge.

Two routes are usually taken by teachers in the classroom to make instruction serve the CEE. One is that the whole lesson is designed in line with the CEE, making instruction more systematic and profound, especially when the knowledge system in new curricular textbooks is neither integral nor deep; another way is to squeeze in CEE questions so that students become familiar and adaptive to the CEE as soon as possible. Instruction goes around the CEE, and this becomes the beliefs of teachers and principles of lesson design and practice. Following are some teachers' comments:

I think that teaching should always be designed and implemented based on the college entrance examination (TI-A-11-Chinese Language).

"We focus on the course book in daily instruction", cause one of our studies is CEE questions, and they are key points in course books, too! So we still center on test points, guided by CEE questions, and make some amendments when necessary (TI-A-11-Physics).

Many teachers believe that there is a nice arrangement of content in new textbooks, close to daily life, which leaves space for teachers' adaption, but too much is unsystematic and part of the knowledge is not accurate. $\mathrm{CEE}$ questions go further and they have to raise the depth of instruction to meet that need.

I'd prefer to link up with the CEE in my class, you see in this class there is much to be finished, but I arranged two CEE questions, same types appeared before (TI-C-10-History).

It is by no means accidental practice by several individual teachers to use the above strategies and teach to the test. We know from the interviews that discussions of curricula content and progress are arranged in their weekly teaching and research activities. Strategies like this are already shared understandings and criteria to be transformed into most teachers’ classroom practice.

\subsubsection{To School: College Enrollment Rate Is a Lifeline}

High school education is not obligatory and national finance support is very limited. Yet recent years' enrollment expansion of higher education brings about a big forward step to it. Expansion and improvement of conditions are obtained through loans from the bank, high schools bear a heavy burden in survival and development. If they want to obtain recognition from parents and enroll more excellent students, the achievement of their students in the CEE does play a major part in gaining social reputation and finance. This enhances the implication of the CEE to a high school's survival and development. The viewpoint from this teacher is commonplace:

To a school, the college enrollment rate (hereinafter CER) is surely a school's lifeblood (TI-A-10-Chemistry)!

The present qualitative study from the perspective of approaches to teaching shows that the new curriculum is limitedly implemented in three high schools. This does not mean that they do not approve of this curriculum reform or show a resistant attitude to it. The core interests of students, parents, and these schools simply have to bow to the CEE in the practice of this spirit.

My school intends to carry out the curriculum reform, and everyone feels the curriculum reform is good. But in reality, test scores are still the most important priority. So students' scores become the only means for the evaluation of teachers. But we understand the principal's dilemma. The competition between schools is very serious, every school tries their best to have a high enrollment rate and have more students. If your school's enrollment rate is low, there are not enough students, your school will not have a good future (TIB-11-English).

In this mighty test-driven education mechanism, teachers adapt, voluntarily or not, to it. Although several teachers have a strong will for reform and really act, they turn out to be basically assimilated by the rewards and punishments mechanism in the school.

When you do it (curriculum reform), I think you have to change leaders' minds first. You cannot implement a curriculum if you fail. Perhaps several of us can understand the curriculum and plans to do so, but eval- 
uation has not changed, and we are forced then to get involved in test-driven works, a lot of them cannot be completely practiced (TI-B-11-Chinese Language).

Schools have no strong educational beliefs and are persistent when faced with survival. More than that, schools in China lack, administered under a power-centralized system, educational ideology, schools sway easily under the pressure of the CEE and its CER. Otherwise, when they fail to develop an ideal consistent with curriculum reform in education, they evolve into a partner of the CEE and thus intensify its control over instruction.

\section{Discussion}

Fullan (1998) has conceptualized education change in the last 40 years into three distinct but overlapping periods of development, labeled "the implementation phase", "the meaning of change phase", and "the capacity for change phase" (Fullan, 1998). The possibilities for teacher ownership of curriculum change are circumscribed by the anchoring of their authority to speak on curriculum matters in the local context of implementation. This anchoring of the teacher voice provides a key to understanding the perennial problem of the transformation of innovative ideas from conception to implementation (Kirk \& Macdonald, 2001). In our opinion, from the inconformity of teachers' curriculum belief and practice, and actually reflects teachers' embarrassed or even distorted situation in work, they do believe in and wish to implement curriculum reform, but they cannot do it and their professionality and initiality are threatened if a corresponding environmental support cannot be really provided from the education system, and there will be no better teaching.

We find that the biggest institutional obstacle to curriculum implementation comes from the CEE. Quite similar to Au's (2007) findings , certain types of high-stakes tests have led to curricular content expansion, the integration of knowledge, and more student-centered, cooperative pedagogies (Au, 2007). But the existing high education is a machine that pivoted the CEE, every part or system operates around it. Although some innovations have been made in the CEE, the limitation of a test-driven instruction cannot be avoided. When instruction adapts to the new test, a new test-driven instruction begins again (Madaus, 1988b).

To a large extent, instruction not at improving students' learning abilities, but at training students how to cope with tests. Teaching and learning are there to speed up the delivery of the content; to expose students to different types of questions and emphasize the skills needed to solve them as well as give them tips for solving the questions; to increase the quantity and difficulty of the questions; and to extend review and test preparation. Even if they enter higher education, higher education institutions still find that students can solve questions but cannot study.

Modern regimes of high-stakes standardized testing in the US represent a form of New Taylorism built upon the curricular legacy of scientific management from the early 1900s. In the process, standardized tests themselves, as a form of measurement, contribute to the implementation of New Taylorism in teaching through the inherent decontextualization and commoditization that such testing requires (Au, 2011). A mere change of CEE content works little to curriculum reform because the curriculum and instruction in high school are different from the CEE in objectives, process, mind features and ways of behavior. The former aims to educate students, to promote a comprehensive development in students' knowledge, competence and attitude, but the latter seeks selection, and differentiation in students. It assesses more knowledge and ability than methods, situation, attitudes or values and cannot contain all the objectives of high school education. Not all the contents of the new curriculum are suitable to be assessed.

Therefore, the CEE cannot be taken as the sole means of evaluating curriculum reform (Zhang, 2007), and a change has to be made not only in CEE content but also the enrollment system of higher education (Zhou, 2005). We have to change the present educative-administration-dominated enrollment system, empower universities with more rights and make them the main power in students' selection. Universities can then pluralize their means and content of assessment and take the CEE as one of their important student selecting bases. We have to include students' learning process, comprehensive ability, sense of social responsibility and service experience in our evaluation list.

It is, of course, not easy to put this reform into effect in China. The function of this standardized, unitary CEE system is not just a means of students' selection, it has some social and political functions, to guarantee the fairness and justice of the consequence of education, for China bears a weak integrity, social justice and professionalism. An individualized pluralistic enrollment system based on university autonomy is destined to meet great challenges from social culture and institutions. Therefore, great resistance exists in CEE structural reform and it 
will be very difficult to develop a cultural and institutional environment for curriculum reform.

\section{Conclusion}

All in all, this study found that curriculum implementation at the classroom level did not fulfill the purpose of the reform. Transmission approaches characterized by teachers lecturing and students listening dominated the teaching and learning. One-third of observed classes take an understanding approach to teaching, but the understanding is standardized, and students are not encouraged to develop diverse perspectives. Although the ideas of curriculum design and textbooks have changed, real change in the classroom is not easy.

\section{Project Information}

This research was supported by The National Social Science Fund of China (Project No. 14BMZ090).

\section{References}

Alderson, J. C., \& Wall, D. (1993). Does Washback Exist? Applied Linguistics, 14, 115-129. http://dx.doi.org/10.1093/applin/14.2.115

Anderson-Levitt, K. M. (2008). Globalization and Curriculum. In F. M. Connelly, M. F. He, \& J. Phillion (Eds.), The Sage Handbook of Curriculum and Instruction (pp. 349-368). California: Sage Publications. http://dx.doi.org/10.4135/9781412976572.n17

Au, W. (2007). High-Stakes Testing and Curriculum Control: A Qualitative Metasynthesis. Educational Researcher, 36, 258-267. http://dx.doi.org/10.3102/0013189X07306523

Au, W. (2011). Teaching under the New Taylorism: High-Stakes Testing and the Standardization of the $21^{\text {st }}$ Century Curriculum. Journal of Curriculum Studies, 43, 25-45. http://dx.doi.org/10.1080/00220272.2010.521261

Brooks, J. G., \& Brooks, M. G. (1993). In Search of Understanding: The Case for Constructivist Classrooms. Alexandria, VA: Association for Supervision and Curriculum Development.

Cazden, C. B. (2001). Classroom Discourse: The Language of Teaching and Learning (2nd ed.). Portsmouth, NH: Heinumann.

Chapman, D. W., \& Snyder, C. W. (2000). Can High Stakes National Testing Improve Instruction: Reexamining Conventional Wisdom. International Journal of Educational Development, 20, 457-474. http://dx.doi.org/10.1016/S0738-0593(00)00020-1

Cheung, D., \& Wong, H. W. (2002). Measuring Teacher Beliefs about Alternative Curriculum Designs. The Curriculum Journal, 13, 225-248. http://dx.doi.org/10.1080/09585170210136868

Dewey (1966). Democracy and Education: An Introduction to the Philosophy of Education. New York: Free Press.

Fenstermacher, G. D., \& Soltis, J. E. (2009). Approaches to Teaching (5 ${ }^{\text {th }}$ ed.). New York and London: Teachers College Press.

Fullan, M. (1998). The Meaning of Educational Change: A Quarter of a Century of Learning. In A. Hargreaves, A. Lieberman, M. Fullan, \& D. W. Hopkins (Eds.), International Handbook of Educational Change (pp. 214-228). New York: Springer. http://dx.doi.org/10.1007/978-94-011-4944-0_12

Fullan, M. (2001). The New Meaning of Educational Change (3rd ed.). New York: Teachers College.

Gardner, H., \& Boix-Mansilla, V. (1994). Teaching for Understanding in the Disciplines and Beyond. Teachers College Record, 96, 198-218.

Hannum, E., An, X. H., \& Cherng, H. Y. (2011). Examinations and Educational Opportunity in China: Mobility and Bottlenecks for the Rural Poor. Oxford Review of Education, 37, 267-305. http://dx.doi.org/10.1080/03054985.2011.559387

Huang, F. Q. (2004). Curriculum Reform in Contemporary China: Seven Goals and Six Strategies. Journal of Curriculum Studies, 36, 101-115. http://dx.doi.org/10.1080/002202703200004742000174126

Jaspers, K. (1983). Was ist Erzighung? Munich: Piper Verlag GmbH.

Kirk, D., \& Macdonald, D. (2001). Teacher Voice and Ownership of Curriculum Change. Journal of Curriculum Studies, 33, 551-561. http://dx.doi.org/10.1080/00220270010016874

Li, X. J. (1990). How Powerful Can a Language Test Be? The MET in China. Journal of Multilingual and Multicultural Development, 11, 393-404. http://dx.doi.org/10.1080/01434632.1990.9994425

Luo, M. (2012). Reforming Curriculum in a Centralized System: An Examination of the Relationships between Teacher Implementation of Student-Centered Pedagogy and High Stakes Teacher Evaluation Policies in China. New York: Columbia 
Univeristy.

Madaus, G. F. (1988a).The Influence of Testing on the Curriculum. In L. N. Tanner (Ed.), Critical Issues in Curriculum (pp. 83-121). Chicago, IL: The National Society for the Study of Education.

Madaus, G. F. (1988b). The Distortion of Teaching and Testing: High-Stakes Testing and Instruction. Peabody Journal of Education, 65, 29-46. http://dx.doi.org/10.1080/01619568809538611

Marcuse, H. (1964). One-Dimensional Man: Studies in the Ideology of Advanced Industrial Society. Boston, MA: Beacon Press.

Miller, J. P., \& Seller, W. (1985). Curriculum: Perspectives and Practice. New York: Longman.

Nickerson, R. S. (1985). Understanding Understanding. American Journal of Education, 93, 201-239. http://dx.doi.org/10.1086/443791

Palmer, P. J. (2007). The Courage to Teach: Exploring the Inner Landscape of a Teacher's Life (10th Anniversary ed.). San Francisco, CA: Jossey-Bass.

Patrick, B. (1978). A Curriculum Orientation Profile. ED 164613.

Popham, W. J. (1987). The Merits of Measurement-Driven Instruction. Phi Delta Kappan, 68, 697-682.

Zhang, Y. N. (2007). Inquiry on the Relationship between New Curriculum Reform and High-Stakes Tests. Curriculum, Teaching Materials and Teaching Methods, 27, 15-17.

Zhou, H. (2008). Twelfth Year of Senior Middle School. (Documentary Independent Film)

Zhou, Y. (2005). Defend the Independent Dignity and the Pursuit of Education: All-Around Education, Curriculum Reform and College Entrance Structural Adjustment. Global Education, 34, 11-13. 